OPRE//TEC

MACMILLAN

\title{
Updating for Business
}

Interviewing Study Guide

Working with People 